\title{
Nathalie Fabry et Sylvain Zeghni (dir.), Tourisme, territoires et développement
}

Revue Mondes en développement, n² 40, De Boeck, 2012, 167 pages

\section{Philippe Duhamel}

\section{OpenEdition}

\section{Journals}

Édition électronique

URL : http://journals.openedition.org/tourisme/222

DOI : 10.4000/tourisme.222

ISSN : 2492-7503

\section{Éditeur}

Éditions touristiques européennes

\section{Édition imprimée}

Date de publication : 1 juin 2013

Pagination : 117-118

ISSN : 2109-5671

\section{Référence électronique}

Philippe Duhamel, « Nathalie Fabry et Sylvain Zeghni (dir.), Tourisme, territoires et développement », Mondes du Tourisme [En ligne], 7| 2013, mis en ligne le 30 septembre 2015, consulté le 22 septembre 2020. URL : http://journals.openedition.org/tourisme/222 ; DOI : https://doi.org/10.4000/tourisme. 222

Ce document a été généré automatiquement le 22 septembre 2020

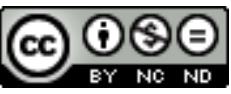

Mondes du tourisme est mis à disposition selon les termes de la licence Creative Commons Attribution - Pas d'Utilisation Commerciale - Pas de Modification 4.0 International. 


\title{
Lectures critiques
}

\section{Nathalie Fabry et Sylvain Zeghni (dir.), Tourisme, territoires et développement}

Revue Mondes en développement, $n^{\circ}$ 40, De Boeck, 2012, 167 pages

\author{
Philippe Duhamel
}

\section{RÉFÉRENCE}

Nathalie Fabry et Sylvain Zeghni (dir.), Tourisme, territoires et développement, revue Mondes en développement, $\mathrm{n}^{\circ}$ 40, De Boeck, 2012.

1 Dans ce numéro de la revue Mondes en développement, Nathalie Fabri et Sylvain Zeghni proposent de s'intéresser aux effets du tourisme dans "la vie économique du pays d'accueil. Quelle est la nature de cette participation? Est-elle de nature à soutenir et à porter la croissance économique des pays récepteurs? Qu'en est-il des déplacements long-courrier pour accéder aux destinations lointaines et de la question du réchauffement climatique? Plus généralement, quelle est la place des pratiques touristiques durables" (p. 8). Les réponses apportées à travers six articles et une annexe "Notes et documents" se distinguent entre plusieurs volets : l'un rassemble trois articles où sont menés une réflexion sur la durabilité ; un autre évoque les retombées économiques à travers un "nouvelle" destination (Cuba) ou une "nouvelle" pratique (le tourisme médical); le dernier volet, rédigé par les coordinateurs, est une réflexion sur le rôle des clusters touristiques dans le développement local.

2 Parmi les premiers articles, le travail de Jean-Paul Céron et Ghislain Dubois est à la fois intéressant et inquiétant, puisqu'il traite du "tourisme dans l'Outre-mer français face à la contrainte carbone". Si l'enjeu est important, si la réflexion est intéressante avec la mobilisation de la notion d'"éco-efficacité" et si les résultats sont inattendus, les scénarios "pour penser l'avenir" surprennent. En effet, ce qui est proposé par les 
auteurs semble assez improbable comme, par exemple, "le développement du tourisme domestique" pour des espaces insulaires peu peuplés (même si on se fonde sur le recours aux populations résidant en proximité régionale, on sait la difficulté dans la réorientation des flux). Quant à "l'accroissement de la durée de séjours" ou à "la croissance de la dépense moyenne", ce sont des vœux pieux évoqués par tous les acteurs du tourisme et sur lesquels, là encore, il est difficile d'agir. Enfin, la première des préconisations est "la diminution de l'intensité des transports aériens", ce qui signifie "une diminution des arrivées, plus ou moins forte selon les marchés de substitution existants" et un recul total estimé de $-5 \%$ à - $23 \%$ (de - $30 \%$ à - $40 \%$ pour les seuls métropolitains). Tout cela est évoqué sans que l'on sache le rôle exact de "chaque secteur dans le total des émissions", ce qui laisse songeur. Au-delà se pose la question de la mobilité des individus et du droit à circuler librement et celui des sociétés à accueillir qui bon leur semblent ou qui est prêt à leur rendre visite. Ici l'action en faveur de l'écologie rencontre la décision politique (qui ne dit pas son nom).

3 Le texte d'Alain Girard et de Bernard Schéou, "Le tourisme solidaire communautaire à l'épreuve des illusions culturaliste et participative. L'exemple d'une expérience au Bénin", est d'une grande clairvoyance et tente de sortir d'une vision manichéenne des situations observées. En effet, à travers l'exemple d'un projet d'association, l'objectif est de montrer que le modèle de développement communautaire proposé par l'association tend "à accroître les difficultés du projet sur le terrain, en générant une absence de prise en compte des logiques d'appropriation du projet par les différents acteurs". Ainsi, le projet de l'association apparait comme extrêmement rigide, en ce qu'il souhaite tout envisager et donc tout déterminer au préalable, dans une vision de ce que devrait être le "bon développement" et la "bonne relation" entre touristes et société d'accueil. Dès lors, les auteurs démontrent les limites, voire les dangers que peut ici constituer une approche participative et culturaliste. Comme quoi, une fois encore, l'enfer est pavé de bonnes intentions.

4 Les autres articles sont plus strictement dans une dynamique de rendre compte de connaissances ou de faire le point. C'est le cas du travail de Géraldine Froger sur "le tourisme durable dans les suds : solution et mirage", de l'article de Rémy Herrera sur Cuba ou de celui de Loïck Menvielle sur le "tourisme médical". Enfin, la réflexion de Nathalie Fabry et Sylvain Zeghni sur les clusters touristiques comme la note de Mohamed Hellal et Mounir Jarraya sur "les perspectives du développement touristique durable dans un territoire insulaire vulnérable" apparaissent davantage comme des réflexions prospectives, voire programmatiques.

\section{AUTEURS}

PHILIPPE DUHAMEL

Université d'Angers 